\title{
The museum as an educational support in a Civil Engineering context
}

\section{Sampaio, Alcinia Zita}

Department of Civil Engineering, University of Lisbon, Lisbon, Portugal.

\begin{abstract}
A Museum, when inserted in a Technical University, is a privileged place for the preservation of the historical memory concerning the construction techniques evolution along ages. The construction industry have been evolved in teaching methods, in the use of specific equipment and applied technologies, and in the way of presenting and making drawing. The Museum presents a reminder of how the technology advanced to the current methodologies of work. The Museum of Civil Engineering of the Instituto Superior Técnico (IST) contains a significant collection of elements offered by teachers and entities which is in exhibition, in a proper room, inserted within the University space. Elements such as: a model of the Pombaline cage, illustrating the constructive technique anti-seismic applied after the earthquake of 1755, that occurred in Lisbon, or the wooden models of roof frames are examples that are preserved and kept in adequate conditions, contributing to the dissemination of the technical heritage and to the memory and history of the Construction. In the context of the congress some elements used to support teaching and related with traditional building technologies are described in detail.
\end{abstract}

Keywords: Museum; Construction; Education; Technology; Heritage. 


\section{Introduction}

The Museum of Civil Engineering of the Instituto Superior Técnico (IST), placed in Lisbon, Portugal, contains a collection of elements related to the construction activity . The elements were restored and maintained, scheduled and organized properly. Each piece is identified and characterized, namely, its place of origin or the identification of the donor and the conservation status at the reception date. The inventory cataloging process follows a thematic organization related to the different areas involved (Sampaio, 2016): Transports, Bridges, Topography, Architecture, Construction techniques and materials, Drawings, Hydraulic and Soil mechanics. For all the pieces on exhibition in the room it was drawn up a descriptive text of its features, functionality, time of use and the number of inventory.

Within the Congress, focuses on higher education, some of the most remarkable elements related to the fields of Architecture, Construction techniques and Drawings, supporting the education activity, are described in detail:

- A wooden model reproducing the anti-seismic structure called "Pombaline cage" forming St. Andrew's crosses, created for the reconstruction of Lisbon, devastated by the earthquake of 1755 . This element is frequently used to support the visit of national and foreigner seismic specialist, as the model represents with fidelity the structural organization of the innovative structural solution created to rehabilitation of Lisbon after. The cage supports the introduction to the reinforced concrete anti-seismic structure currently applied;

- In addition several wooden models of roof frames of buildings and samples of carpentry interior elements like stairways and doors, are exposed. Those models made in wood identifies interior details applied in staircases and body guards, used in buildings design in the beginning of sec. XIX, so it is used to introduce this architectural era frequentlu used at that time in aristocratic houses n Portugal;

- The Museum has a wide collection of drawings executed by students, representing components, dating back since the formation of the IST until after the Second World War. Currently, the discipline of technical drawing promotes, in each semester, a session presented at the Museum, so students can confront the contemporary track, based on current standards, with the held at the time. Drawing devices are also exposed, clarifying, students and visitors, with the use of scale rulers, squares and " $\mathrm{T}$ " rulers;

- The Museum contains the re-creation of the work room of the architect Álvaro Machado, first professor of architecture at the IST, and a collection of drawings of their projects. The Museum also contains plaster models of masonry vaults and portals and wooden models of decorative and functional emblematic elements, that are currently used in Art of History classes. The drawings are used to support old 
methodologies of representing projects as they are confronted to current definitions of technical drawings.

\section{The Museum}

The Museum of Civil Engineering was inaugurated on December $20^{\text {th }}, 1993$, on the ground floor of Civil Engineering Pavilion of IST. Until the creation of the Museum, educational materials, not in use, were found in professor's offices, laboratories and classrooms. Other elements of interest related to the areas of knowledge developed in the Department, have been donated to the Museum. The Museu room presents regularly exhibitions of pedagogical character and is regularly changed in order to allow the exhibition of all its spoils (Figure 1). The students are invited to attend lectures on the diverse type of theme that supports the exhibitions' opening.

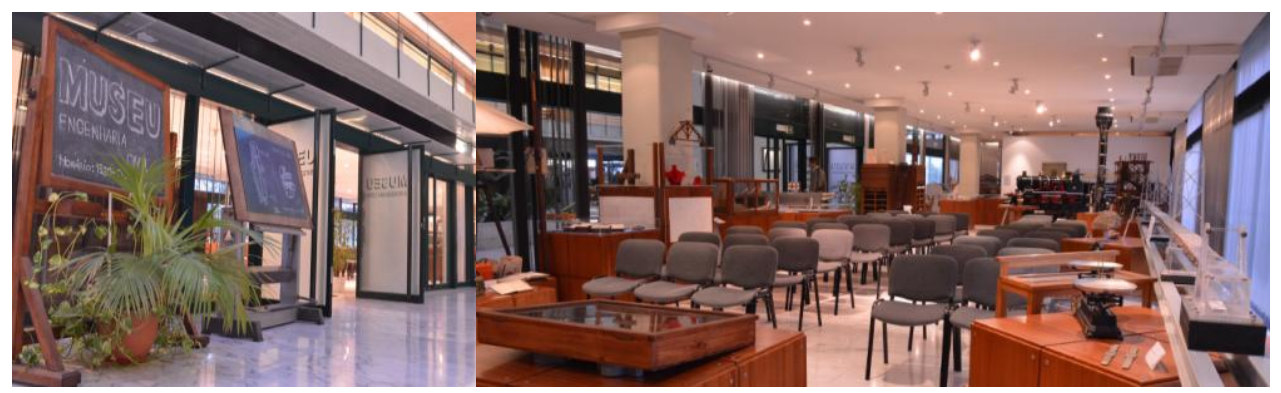

Figure 1: Out-side and in-side views of the Museum.

As the school is a space of several international events, namely, conferences and technical meetings, the Museum became an interesting place for national and international visitors. Supporting this interest, the current direction promoted the identification of all elements and the linked text, in Portuguese and English languages. So the Museum provides to:

- Students, an organized documentation of interest for research works conducted by graduate or PhD students,.

- Teachers, the complementarity of disciplines providing support to the programmatic curriculum, with the description of old equipment. Namely concerning hydraulics, construction process or technical drawings;

- Visitors, an important collection of books, photographs, drawings, models and equipment related to the construction industry. 


\section{Wooden models}

\subsection{Pombaline cage}

The wooden model of a Pombaline cage reproduces the anti-seismic structure type, designed for the reconstruction of Lisbon, devastated by the earthquake of 1755. It was created under the Ministry of Marquis of Pombal, in the reign of king José I, and it was applied in buildings until the end of the first quarter of the $20^{\text {th }}$ century. The Pombalin buildings presents a structure composed of vertical, horizontal and sloped wooden elements, allowing a good capacity to resist to seismic loads (Figure 2).

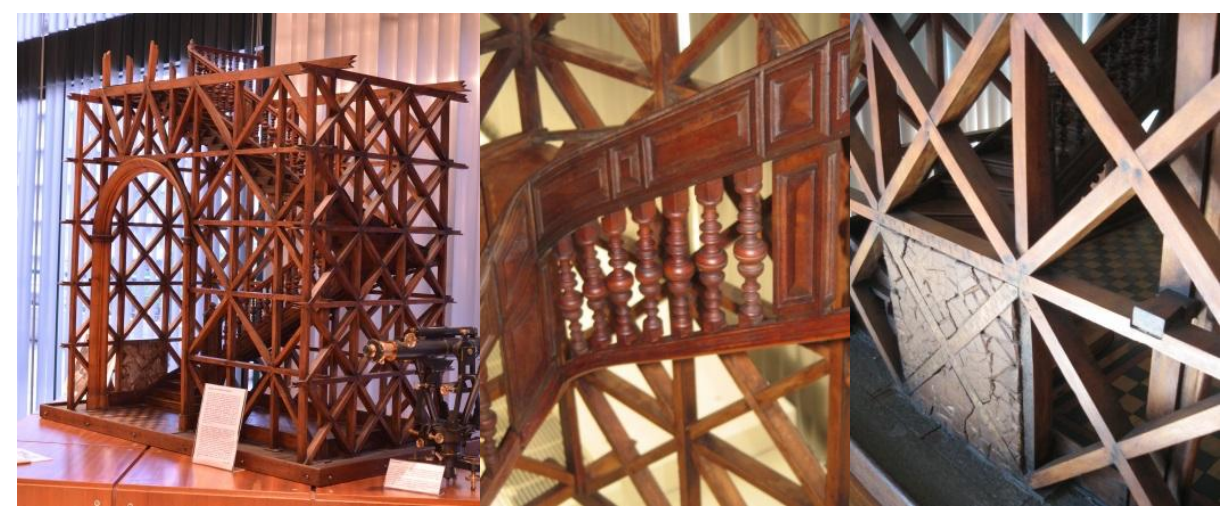

Figure 2: The Pombaline cage.

The structure draws a St. Andrew's cross: the frechais are horizontal wooden beams, allowing the support of vertical elements; the horizontal locking way is established by travessanhos, enclosed in vertical panels, and by spars located over the spans; the link between the cage and the masonry is achieved by hands, which are pieces of wood presenting a tooth shape (LNEC, 2008). From a structural point of view, the Pombaline cage consists of a three-dimensional truss structure in wood, resulting from the interconnection of several flat structural panels. Each one consists of a set of wooden bars forming triangles. This is the only geometric figure that cannot be deformed without varying the length of their edges. This is still the same concept used today in metallic structures. This still is a correct structure, that needs to be preserved in refurbishing works applied over old buildings, and students see the real structural organization of wooden elements established at that time. The cage presents the capacity to withstand the horizontal forces in any direction, as earthquakes induce in the building structure. As the bars resist well to this type of deformation, the cage allows an adequate resistance to horizontal forces, caused by seismic vibrations of the soil. So, with this wooden truss the buildings have the ability to transmit horizontal forces to the foundations, surviving to the earthquakes effect 
with more or less damage raised in the building (Lopes \& Bento, 2005). So, this issue is frequently supported by the cage shown and described by teachers.

\subsection{Roof coverings trusses}

The typical Portuguese wood coverage uses trusses as the main structural element, with a pending variable between $20^{\circ}$ and $30^{\circ}$ (Figure 3). Typically, the wood coverings consist of simple trusses, born probably in the Renaissance, or the truss of Palladio that emerged in the 16th century, with average spans between 6 and 7 meters. The simple trusses have an elementary geometry, triangulation, consisting of a horizontal line, by two sloped legs, for the formation of the roof shed, by a middle vertical element, tight at the apex of the roof by the legs, and Palladio truss with more two sloping struts connecting the legs to the base of the vertical element. The ancient form of interconnect elements is through finger joints, which have teeth and, eventually, even of gleaning and mecha (Figure 4). From the 19th century, the links have been replaced with metallic elements such as: nails, screws, bolts, metal bands, chicken feet and "T"s.

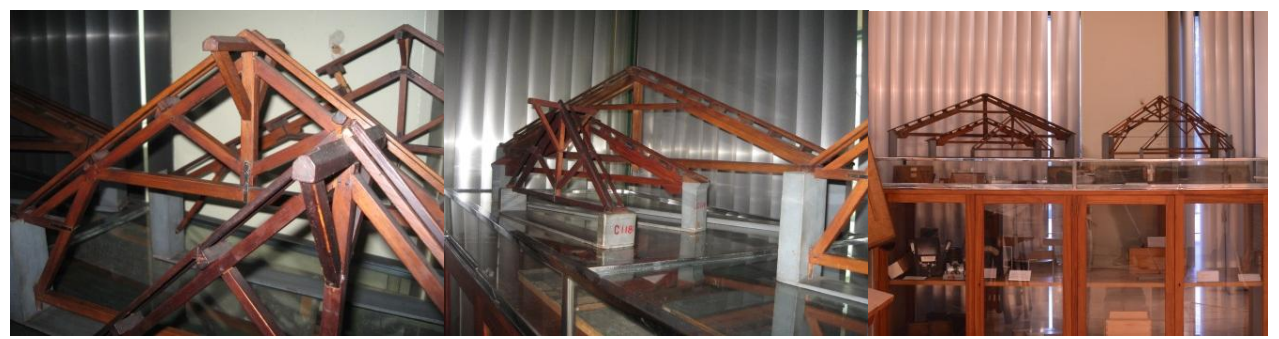

Figure 3: Wooden coverings trusses.

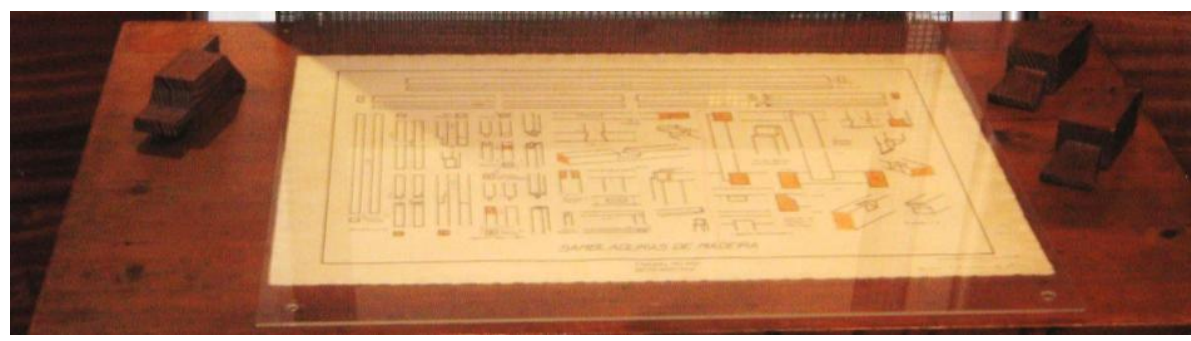

Figure 4: Ancient form of interconnect elements: models and drawing.

The models represent various type of bearing structure used in old roofs, serving to support the teaching of subjects related to Construction Processes and Structures. The spatial organization of the linear elements is still the basis of the project of metal structures. Civil engineering students often carry out visits to the Museum in order to understand the structural organization applied in old roofs. The templates serve to complement the students' training. 


\section{Atelier of architect}

The architect Álvaro Machado (1874 - 1944) was the first teacher of Architecture at the IST of the Technical University of Lisbon, from 1911 to 1936 . The room recreates the atelier of the architect, installed in one of the room of their house, in Lisbon, and the contents of the room were offered to the IST, by their daughters, in 2000. The work place was meticulously built by Machado, since 1910, over years of use. All the furniture was designed by him, and it composed of desk, tripod support, bookcase and banks. The organization of the walls was the target of a careful record left by him, facilitating the reconstitution presented in a specific room built inside the Museum space (Figure 5). The selected elements includes: paintings and drawings of their architectural projects; drawings and paintings made by colleagues and friends, namely Raul Lino, Ezequiel Pereira and Miguel Queriol; draft scenarios designed by his father; portraits of masters like José Luis Monteiro and from himself painted by Constantino Fernandes and Ferreira da Costa. The drawings are made with pencil, ink and watercolor on paper. Some of their architectural designs are placed in the archive of the IST (Caldas \& Pera, 2002).

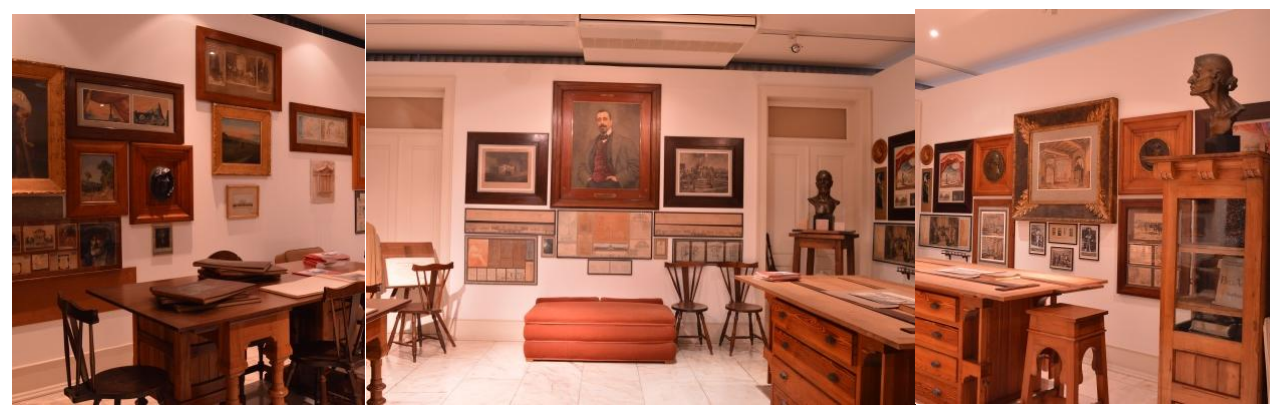

Figure 5: The re-creation of the work room of the architect Alvaro Machado.

\section{Technical drawings}

\subsection{Architectural drawings}

According to the publication co-hosted by John v. Caldas, on the occasion of the opening of the replica of the atelier, the architect, in the designer, he was the author of a vast work (Caldas \& Pera, 2002). Some of the designs, organised in the framework of competitions, works were also donated, complementing the furniture and belongings.

Figure 6 presents pencil drawings, ink and watercolour on paper of architectural projects. 


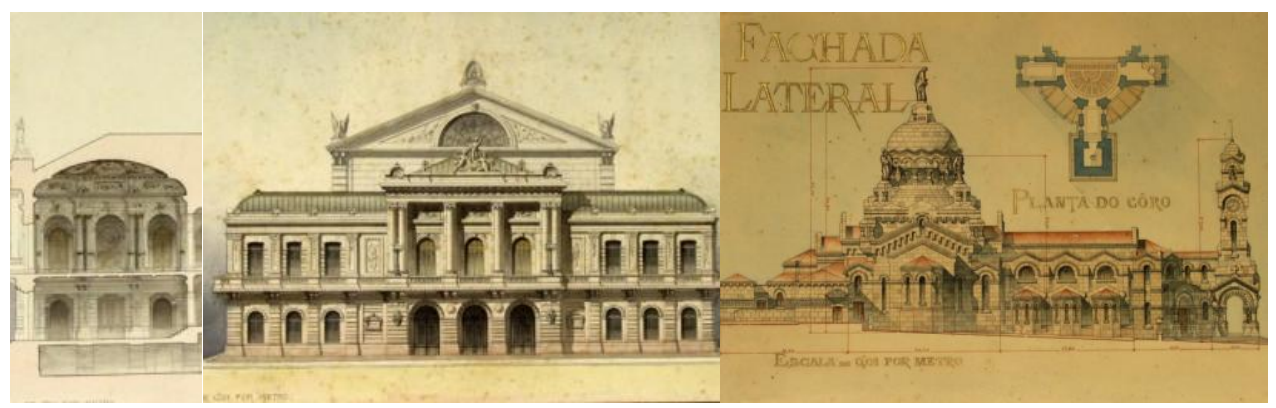

Figure 6: Pencil drawings, ink and watercolour on paper of architectural projects.

In the same booklet, António Ressano Lamas says that "the quality of the drawings and the aesthetic and historic interest of the environment preserved were notable and could not immediately be dispersed" and so the IST zela "for your documents and projects and open to researchers to study his work".

\subsection{Construction drawings}

The Museum has a huge collection of drawings executed by students, dating back since the formation of the IST until after World War II. Currently, the discipline of Technical Drawing promotes, in each semester, a session at the Museum, so students can confront the current way of representing technical documents, based on current standards, with the mode of drawing at that time. Teacher exposes the key aspects of differentiation between old and new drawings, in particular, the format of the drawing sheet, the type of stroke and the applied colors, the mode of doing annotations and how to insert the dimensions, as well as the evidence rigor of the old drawings execution (Figure 7).
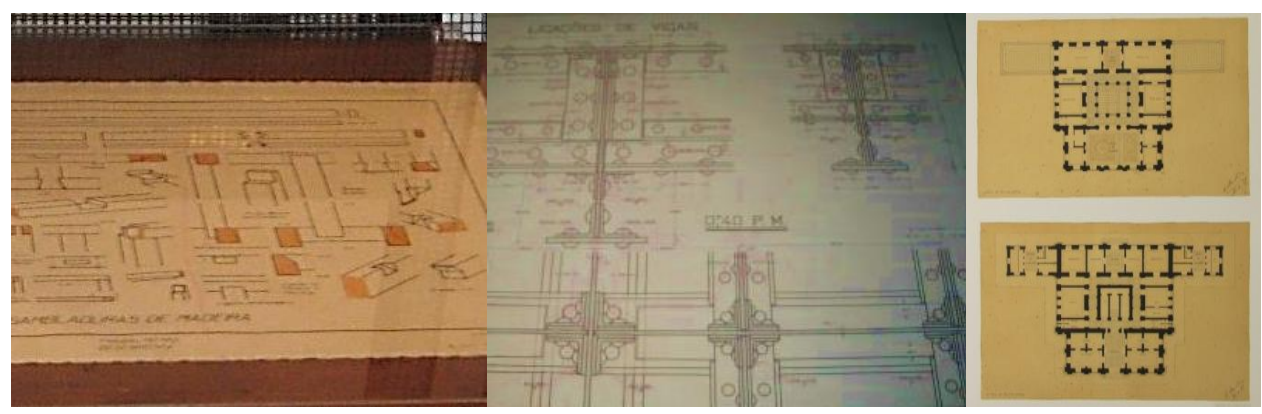

Figure 7: Drawings of masonry and metallic structures and of a Machado's project.

\subsection{Material and tracing tools}

Diverse type of tools used to trace drawings is also in exhibition in the Museum. The vast set of elements clarify, students and visitors, about the old process of making drawing, based in the use of pencils, ink or watercolor, and how to use scale rulers, squares and "T" 
rulers (Figure 8). The presentation of these drawing devicesallows students and visitor to follow the evaluation of the way of tracing technical drawings.

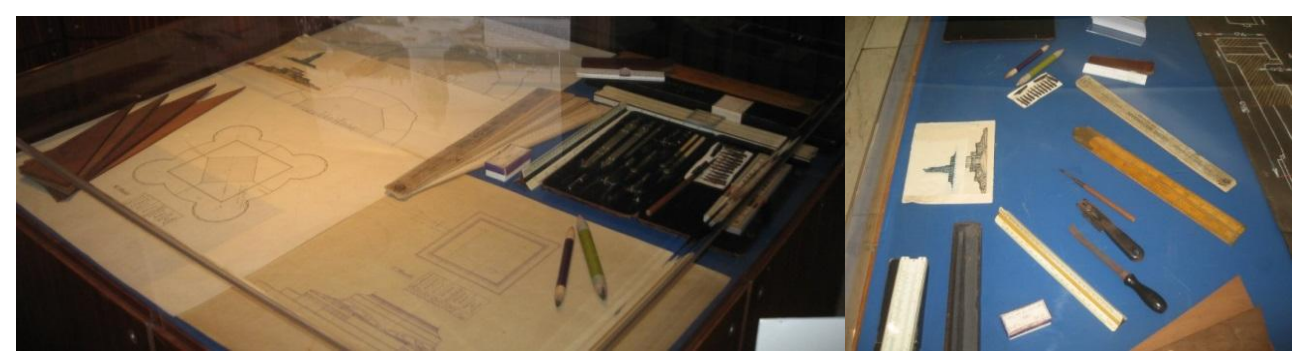

Figure 8: Drawing tools.

\section{Conclusions}

In the history of the construction, process methodologies and scientific knowledges about material and its behavior, have been evaluating to the actual mode of construct buildings. The set of elements described in the text, was collected and kept in a Museu, and they are in exhibition in a proper space, integrated in an engineer school, the IST. The Museu has an important role in the dissemination of old construction methodologies contributing to a better understanding of the current building processes and applied materials. The described elements confirm the effective advances that occurred in construction knowledge, methodologies and material. The Museu also supports the historic identity of the school.

The Museu contains several models made in wood probably executed by students in the workshops implemented in the school by Bensaude, his founder, and as a new pedagogical methodology more practical. In the context of the present Congress some constructive processes were described in detail (a Pombaline cage, a set of wooden trusses, two models of stairs and railings) as well as an atelier of the architect Álvaro Machado, and its drwaings. These elements illustrate processes and methodologies that are not in use today but they should be known to support teaching of old uses and methodologies concerning civil engineering and architecture activity. The Museum is currently used as an educational space, as a research archive of old construction technologies and as a room where engineering-related events take place. The Museum serves the community and preserves the historical memory of the construction activity.

\section{References}

Bensaude, A. (1922) Historical-pedagogical notes about the Instituto Superior Técnico, Lisbon, http://alfredobensaude.ist.utl.pt/nucleos/nucleo/id/3/paginaid/24 
Caldas, J. V. \& Pera, M. T. (2002) Álvaro Machado, first professor of architecture of the IST-exhibition of the donated estate, Instituto Superior Técnico (IST), Museum of Civil Engineering, Lisbon, Portugal.

LNEC (2005) The cage as the genesis of the Anti-Seismic Construction, (in portuguese), Department of seismic engineering and structural dynamics, http://wwwext.lnec.pt/LNEC/DE/NESDE/divulgacao/gaiol_const_sism.html.

Lopes, M., Bento, R. (2005) The Pombaline building (in portuguese), workshop History and science of catastrophe, Institut of Contemporary History, Lisbon, 2005. http://www.civil.ist.utl.pt/ rbento/css/CursoIHC_2005.PDF

Sampaio, A. Z. (2016) The Museum of Civil Engineering of the IST, Museum of Civil Engineering, Instituto Superior Técnico, Lisbon, Portugal, 2016, http://museudec.tecnico.ulisboa.pt/

Silva, P., Pereira; M. F., Soares, F. (2011). The genesis of the Instituto Superior Técnico Alfredo Bensaude. Ed. Althum.com, http://narq.tecnico.ulisboa.pt/extensao-cultural-eeducativa/exposicoes-fisicas-eou-virtuais/a-genese-do-tecnico-alfredo-bensaude/ 